\title{
ANALISIS PENINGKATAN KONSISTENSI ILMIAH SISWA PADA PEMBELAJARAN DENGAN MENGGUNAKAN PENDEKATAN SCIENTIFIC BERBASIS MULTIREPRESENTASI
}

\author{
Iyon Suyana ${ }^{1}$, Shelly Feranie ${ }^{1}$ \\ ${ }^{1}$ Universitas Pendidikan Indonesia, Jl Dr Setiabudi No 229, Bandung , 40154 \\ *) Email: iyons@upi.edu
}

\begin{abstract}
Abstrak
The research aimed to determine the improvement and description of students' scientific consistency in a senior high school after learning using scientific approach based on multiple sepresentasi. The sampel of the research was 31 students with purposive sampling method. The research method used was quasi-experiment with one shot case study design experiment. To determine the studens' scientific consistency, three-tier test with verbal question, image and mathematical question were applied. The result showed that there is an improvement of students' scientific consistency in medium category, and for some particular subconcepts showed the improvement in low, medium and high categories.
\end{abstract}

Keywords: scientific consistency, multirepresentation scientific approach

\section{PENDAHULUAN}

Representasi merupakan suatu konfigurasi bentuk atau susunan yang dapat menggambarkan, mewakili, atau melambangkan sesuatu dalam suatu cara [2]. Representasi merupakan adalah suatu simbol atau gambaran yang mewakili suatu objek atau proses [6]. Multirepresentasi merupakan merepresentasi ulang suatu konsep yang sama, namun dalam bentuk yang berbeda. Contoh penggunaannya dalam fisika adalah verbal, gambar, tabel, grafik, persamaan matematis, simulasi komputer, dan lain-lain. Beberapa bentuk representasi yang lebih konkrit (misalnya sketsa atau diagram gaya) berfungsi untuk menjelaskan konsep yang abstrak, seperti percepatan dan hukum II Newton. Penggunaan representasi akan membantu siswa untuk memahami materi. melatihkan keterampilan representasi, yaitu kemampuan yang harus dibangun dan dimiliki untuk dapat memecahkan masalah yang terjadi secara tepat [5]

Konsistensi ilmiah merupakan kemampuan siswa untuk menjawab sebuah persoalan dengan benar dan dapat dibuktikan secara ilmiah. Dalam proses belajar, siswa dihadapkan/menemukan berbagai macam persoalan dengan berbagai macam representasi [1]. Kemampuan konsistensi ilmiah ini diharapkan dapat membantu siswa dalam menjawab berbagai permasalahan yang diberikan. konsistensi respon siswa terhadap berbagai representasi suatu konsep fisika tertentu menunjukkan pemahaman konsep yang mantap [5]. Konsistensi ilmiah ini dapat diukur dengan cara mengukur suatu konsep dalam berbagai representasi menggunakan instrumen Three-Tier Test, yaitu instrumen yang berisikan permasalahan atau soal, pilihan alasan atas jawaban yang diberikan, dan tingkat keyakinan siswa akan jawaban yang diberikan. Hasil pengukuran dapat mengidentifikasi masalah-masalah siswa; apakah siswa tersebut memiliki pemahaman konsep yang kurang akan suatu materi tertentu atau siswa tersebut memiliki kesulitan dalam menerjemahkan suatu persoalan yang disajikan dalam satu bentuk representasi kedalam bentuk representasi lainnya. Hal ini diakibatkan karena proses pembelajaran yang tidak melatihkan kemampuan konsistensi ilmiah ini. Oleh karena itu, dibutuhkan metode pembelajaran yang dapat meningkatkan konsistensi ilmiah. Salah satu bentuk pembelajaran yang diharapkan mampu melatihkan kemampuan ini adalah dengan pendekatan scientific.

Pembelajaran dengan pendekatan scientific adalah pembelajaran yang terdiri atas kegiatan mengamati 
(untuk mengidentifikasi hal-hal yang ingin diketahui), merumuskan pertanyaan (merumuskan hipotesis), mencoba/ mengumpulkan data (informasi) dengan berbagai teknik, mengasosiasi/ menganalisis/ mengolah data (informasi), dan menarik kesimpulan serta mengkomunikasikan hasil yang terdiri dari kesimpulan untuk memperoleh pengetahuan, keterampilan, dan sikap. Dengan demikian, diharapkan pembelajaran dengan pendekatan scientific berbasis multirepresentasi dapat meningkatkan konsistensi ilmiah pada siswa SMA.

Pembelajaran merupakan cara dan wadah bagi seseorang untuk dapat memperoleh pengetahuan dan digunakan sebagai bekal dalam kehidupan sehari-hari. Namun, nyatanya masih banyak kekurangan yang dimiliki dalam proses pembelajaran yang sering kita temui, antara lain adalah kurangnya pemahaman konsep dan konsistensi ilmiah yang dimiliki oleh siswa. Bagaimana cara meningkatkan konsistensi ilmiah tersebut? Cara untuk meningkatkan konsistensi ilmiah siswa salah satunya adalah dengan penerapan pembelajaran dengan pendekatan scientific berbasis multirepresentasi. Penerapan pembelajaran ini dapat terukur dengan menggunakan instrumen Three-Tier Test yang berisikan permasalahan atau soal, alasan atas jawaban permasalahan, dan tingkat keyakinan siswa atas jawaban yang telah diberikan.Sehingga tingkat konsistensi ilmiah yang dimiliki oleh siswa dapat teridentifikasi dengan menggunakan instrumen ini.

\section{METODE}

Subjek Penelitian Adalah 31 orang siswa di salah satu SMA Kelas XI di Bandung. Desain Penelitiannya adalah:

Tabel 1 Desain Penelitian Pre-test and Posttest Design

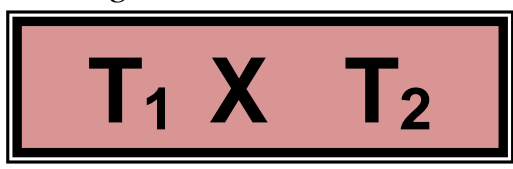

Keterangan :

$\mathrm{T}_{1}$ : Test awal untuk mengetahui kemampuan konsistensi ilmiah awal siswa

$\mathrm{T}_{2}$ : Test akhir untuk mengetahui kemampuan konsistensi ilmiah akhir siswa

$\mathrm{X}$ : Pembelajaran dengan pendekatan sciemtifik berbasis multirepresentasi.

Konsistensi ilmiah yang diteliti pada konsepkonsep suhu dan kalor (1), Fluida statis (2) dan Alat-alat optik (3). Adapun model pembelajaran yang digunakan adalah Learning Cycle $7 E(1)$, Five Stage Conceptual Teaching Model Berbantu Hands-On Activity (2), Five-Stage Conceptual Teaching Models(3)

Intrumen three tier tes dengan tiga representasi masing-masing: verbal, gambar dan matematis. Hasil pretes dan postes diolah dengan menggunakan tabel [6].

Untuk mengetahui peningkatan konsistensi ilmiah dilakukan perhitungan gain skor hasil postes dan pretes dengan menggunakan persamaan dari Hake (1999) berikut .

$$
\langle g\rangle=\frac{(\%\langle S f\rangle-\%\langle S i\rangle)}{100-(\%\langle S i\rangle)}
$$

$S f$ dan $S i$ adalah skor postes dan pretes

\section{HASIL DAN PEMBAHASAN}

\section{A. Peningkatan Konsistensi Ilmiah}

Dari data yang telah diperoleh sampai saat untuk konsep-konsep suhu dan kalor, Fluida Statis, dan Alat-alat Optik semuanya menunjukkan terjadi peningkatan konsistensi ilmiah

Tabel 2. Gain Ternormalisasi Tiap Konsep

\begin{tabular}{ccc}
\hline n-Gain & Konsep & kategori \\
\hline 0,63 & Suhu dan Kalor & sedang \\
\hline 0,53 & Fluida Statis & sedang \\
\hline 0,42 & Alat-Alat Optik0 & sedang \\
\hline
\end{tabular}

\section{B. Peningkatan konsistensi Ilmiah Konsep Suhu dan Kalor}

Peningkatan konsistensi ilmiah siswa setelah dilakukan pengolahan data dengan menghitung nilai 
gain dinormalisasi diperoleh nilai sebesar 0,63 yang artinya peningkatan konsistensi ilmiah siswa termasuk ke dalam kategori sedang. Dari grafik 1 Nampak pada hampir semua sub konsep peningkatan konsistensi ilmiahnya termasuk sedang. Pada sub konsep Kalor laten peningkatannya berkategori rendah. Sedangkan untuk Sub Konsep kalor jenis, Sub Konsep Pemuaian Panjang, Sub Konsep pemuaian volume, dan perpindahan kalor secara konduksi termasuk ke dalam kategori tinggi. Peningkatan yang paling tinggi pada sub konsep kalor jenis.

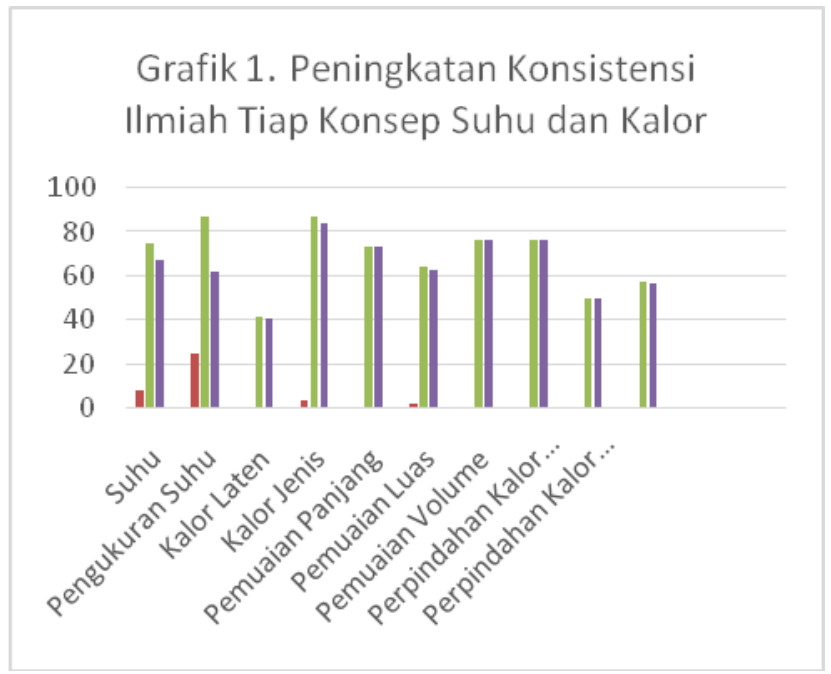

Dari Grafik. 2 dapat dilihat dari jumlah siswa yang konsisten peningkatannya bervariasi dengan sub konsep kalor jenis yang paling tinggi yaitu 20 orang siswa (62\%) sedangkan yang paling rendah adalah pada sub konsep kalor laten hanya 2 orang. Empat sub konsep peningkatan jumlah siswa yang mengalami peningkatan konsistensi ilmiah di atas $50 \%$, yaitu kalor laten, pemuaian panjang, pemuaian volume dan konduksi.

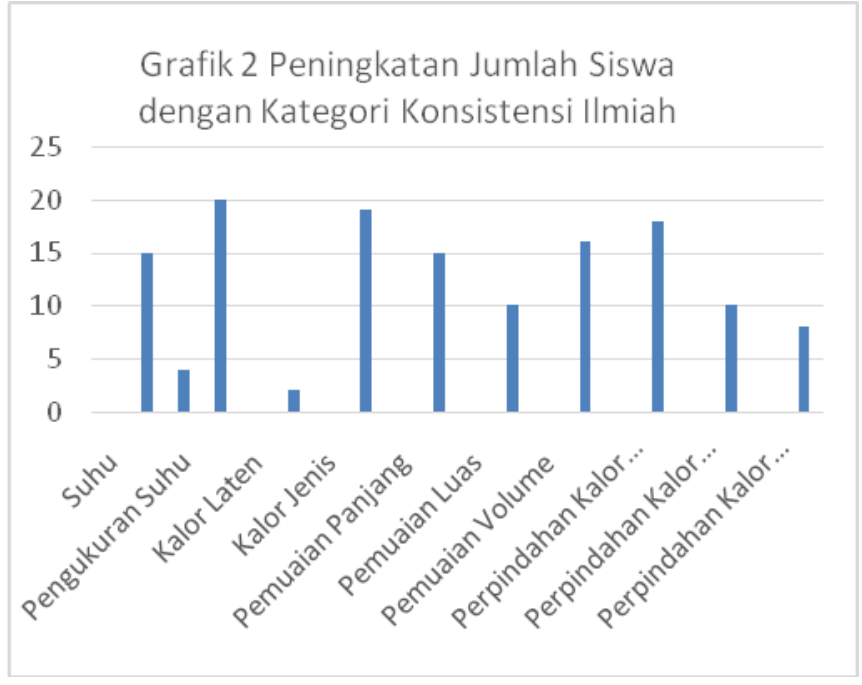

\section{Peningkatan konsistensi Ilmiah Konsep Fluida Statis}

Nilai gain ternormalisasi yang didapat adalah 0,53 dan berada dalam kategori sedang. Jika ditinjau lebih rinci lagi (grafik 3) peningkatan konsistensi ilmiah terjadi di setiap sub konsep setelah penerapan Five Stage Conceptual Teaching Model Berbantu Hands-On Activity.dengan kategori nilai gain yang dinormalisasi berbeda-beda. Sub-sub konsep tekanan hidrostatis, Hukum Hidrostatika, dan gaya apung termasuk kategori tinggi dengan nialai gain ternormalisasi yang paling tinggi pada peningkatan konsistensi sub konsep tekanan hidrostatis. Sedangkan peningkatan pada sub-sub konsep lainnya, yaitu : hubungan tekanan hidrostatis dengan massa jenis, prinsip pascal, terapung, melayang, tenggelam, tegangan permukaan, dan kapilaritas termasuk kategori sedang, dengan gain ternormalisasi yang paling kecil pada sub konsep prinsip pascal 


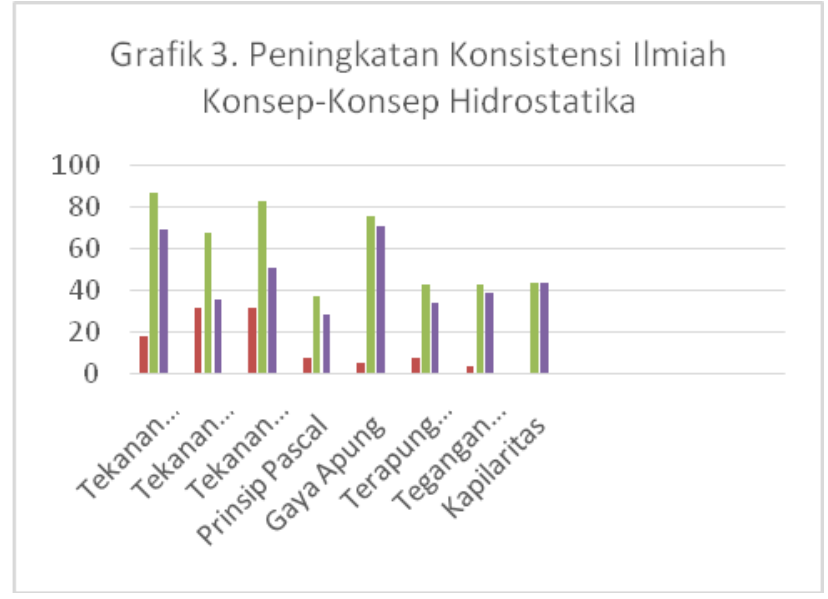

\section{Peningkatan konsistensi Ilmiah Konsep Alat-alat Optik}

Secara keseluruhan konsistensi ilmiah siswa pada konsep kalor dan perpindahannya meningkat dengan gain ternormalisasi rata-rata 0,43 yang termasuk kategori sedang. Sebelum dilakukan pembelajaran Five-Stage Conceptual Teaching Models ini, konsistensi ilmiah siswa hanya tiga sub konsep (kamera, teropong pantul, dan periskop) yang tergolong sedang, yang lainnya rendah. Setelah perlakuan

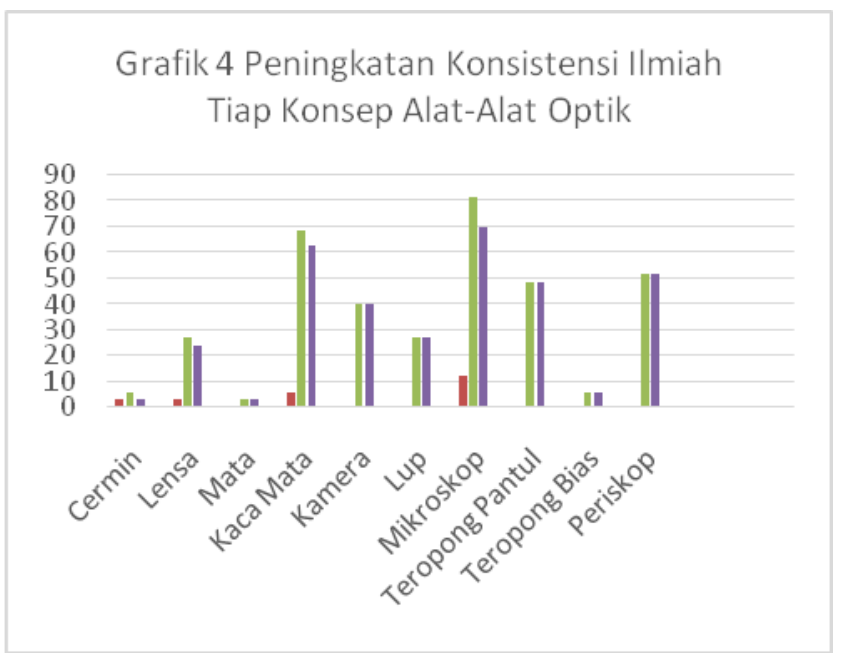

Konsistensi ilmiahnya hanya dua sub konsep yaitu ( kaca mata dan mikroskop) yang menunjukkan nilai baik, tiga sub konsep kamera, teropong pantul dan periskop) menunjukkan pencapaian sedang, sedang yang lima lagi masih rendah. Namun secara keseluruhan rata-rata peningkatan kemampuan konsistensi ilmiahnya termasuk kategori sedang ini ditunjukkan oleh nilai gain ternormalisasinya 0,42 .

\section{E. Model Pembelajaran dan Peningkatan Konsistensi Ilmiah}

Dari data yang telah diperoleh sampai saat laporan ini di buat semua model pembelajaran yang digunakan meningkatkan konseistensi ilmiah dengan kategori sedang. Walaupun nilai gain ternormalisasi rata-ratanya ada perbedaan. FiveStage Conceptual Teaching Models diterapkan pada pembelajaran konsep yang berbeda menghasilkan gain ternormalisasi yang sedikit berbeda walauapun masih dalam kategori yang sama. Dalam penelitian ini masih terlalu dini membandingkan pengaruh perbedaan model pembelajaran terhadap peningkatan konsistensi ilmiah.

\section{SIMPULAN}

Telah terjadi peningkatan konsistensi ilmiah setelah pembelajaran pada konsep suhu dan kalor, Fluida Statis dan Alat-alat optik dengan kategori sedang. Peningkatan konsistensi ilmiah untuk beberapa sub konsep. termasuk kategori tinggi seperti sub-sub konsep kalor jenis, Sub Konsep Pemuaian Panjang, Sub Konsep pemuaian volume, dan perpindahan kalor secara konduksi pada konsep suhu dan kalor tekanan hidrostatika dan gaya apung pada konsep Fluida Statis, dan kaca mata dan mikroskop pada konsep optik. Belum terlihat perbedaan pengaruh model pembelajaran terhadap peningkatan konsistensi ilmiah.

\section{Ucapan Terima Kasih}

Artikel ini bagian dari Penelitian Peningkatan Mutu Pembelajaran yang didanai oleh Lembaga Penelitian dan Pengabdian pada Masyarakat (LPPM) Universitas Pendidikan Indonesia.Terima kasih Kami sampaikan pada yang LPPM UPI yang telah membantu sehingga artikel ini dapat terwujud.

\section{Daftar Acuan}

Duch, B. J., Groh, S. E., Allen, D. E. The Power of Problem Based Learning. Virginia: Stylush Publising, LLC (2001).

Dufresne, R. J, et al. Solving Physics Problem with Multiple Representation.USA: Department of 
Physics \& Astronomy and Scientific Reasoning Research Institute (1997).

[3] Hake, R.R. Analizyng chane/gain scores. American Educational Research (1999). 3.010108 .

[4] Iswanto. Upaya Meningkatkan Aktivitasdan Hasil Belajar Matematika Siswa melalui Pendekatan Cooperative Learning Tipe JigSaw pada Pokok Bahasan Sifat-sifat Bangun Ruang Sederhana. Skripsi pada PGSDFIP UPI Bandung: tidak diterbitkan (2011).

[5] Kohl. P, B et al. Strongly and weakly derected approaches to teaching multiple representation use in physics Education Reasearch (2007). 3. 010108

[6] Nieminen et.al. Force Konsept inventorybased multiple-choice test for investigating student's represaentational consistency, Physics Education Reseaarch (2010). 020109.

[7] Schreyer Institute for Teaching Excellence ŠPenn State Š301 Rider Building II ŠUniversity Park, PA 16802.

[8] Utari,S., Alfiani, Feranie,S., Aviyanti,L., Sari,I.M., Hasanah,L. Application of Learning Cycle 5e Model Aided Cmap tools-Based Media Prototype to Improve Student Conceptual mastery. Applied Physics Research (2013). Vol.5, No. 4. 
